\title{
PENGEMBANGAN DESA WISATA EDELWEISS DI DESA WONOKITRI KECAMATAN TOSARI KABUPATEN PASURUAN \\ (Resort PTN Gunung Penanjakan Taman Nasional Bromo Tengger Semeru)
}

\author{
Tityas Indra Pratiwi ${ }^{a}$, Tatag Muttaqin ${ }^{\mathrm{a}}$, M. Chanan ${ }^{\mathrm{a}}$ \\ aJurusan Kehutanan, Fakultas Pertanian-Peternakan, Universitas Muhammadiyah Malang \\ Jalan Raya Tlogomas No. 246, Malang 65144, Jawa Timur \\ *Email : tityas67@,gmail.com
}

\begin{abstract}
Edelweiss for the tenggerese is the sacred plant, when the Edelweiss became extinct then it will affect the cultural customs of tenggerese. To cope with the extinction of the Edelweiss TNBTS party empower indigenous peoples by creating a tourist village of Edelweiss to maintain continuity, Edelweiss and used to meet the needs of the indigenous. Edelweiss as indigenous because needs as a form of devotion to the deities match the trust community Perched on the Wonokitri. This research aims at 1) to determine the strategy of the development of Village Tourism Edelweiss, 2) to find out the participation of the community. The method used a qualitative descriptive analysis is used to find out the participation of the community. The SWOT analysis is used to determine the development strategy of the tourist village of Edelweiss and continued with the analysis of the SWOT matrix. Research results indicate that the development is done Developing Tourism towards Community Based Tourism; utilization and optimization of tourist attractions with the tourist destination with the elements of education, conservation, culture and economic activity of the community; build and improve the means and infrastructure maintenance tourism is necessary; and increase the promotion and development of better program to attract tourists; as well as conducting training to foster community empowerment and raising public awareness about the management of the tourist village. Participation form community \pm 20 persons became a member of the Edelweiss group of farmers manage tourism village of Edelweiss and society did not enter the participating farmers group planted in front of the Edelweiss home and along the way as well as just promoting tourism.
\end{abstract}

Keywords: Village, Tour, SWOT, Strategy

\section{PENDAHULUAN}

Pariwisata merupakan suatu keseluruhan elemen-elemen terkait yang didalamnya terdiri dari wisatawan, daerah tujuan wisata, perjalanan, industri, dan lain sebagainya yang merupakan kegiatan pariwisata (Devy \& Soemanto, 2017). Pariwisata telah memberikan devisa yang cukup besar bagi berbagai negara di dunia. Pariwisata dianggap sebagai suatu alternatif di dalam sektor ekonomi untuk mengentaskan kemiskinan. Pengembangan pariwisata yang telah dilakukan oleh pemerintah maupun swasta telah meningkatkan jumlah kedatangan wisatawan dari suatu daerah ke daerah yang lain.

Desa Edelweiss Wonokitri terletak di Desa Wonokitri, Kecamatan Tosari,
Kabupaten Pasuruan. Desa ini merupakan wilayah peyangga Resort PTN Gunung Penanjakan, Seksi PTN Wilayah I. Masyarakat di Wonokitri masih memegang teguh adat dan budaya Tengger. Desa Edelweiss Wonokitri dikelola oleh Kelompok Tani Desa Edelweiss Hulun Hyang.

Program taman Edelweiss juga menjadi bagian dari program pemberdayaan masyarakat yang mendukung branding TNBTS sebagai "Land of Edelweiss" atau "Surga Edelweiss". Program tersebut sedang dijalankan di Desa Wonokitri yang masih dalam penggarapan budidayanya. Taman Edelweiss merupakan gerakan gotong royong menuju keselarasan antara 
pengelolah kawasan konservasi TNBTS dan budaya Tengger.

Hasil penelitian Andajani, dkk menunjukkan bahwa "uraian analisa SWOT dan strategi yang bisa dilakukan untuk mewujudkan sebagai kawasan Agropolitan di Desa Mojo dan Mayanggeneng Kecamatan Kalitidu. Strategi yang ditemukan ini menjadi rujukan untuk diwujudkan dalam program nyata di desa" (Andajani, Widjaja, \& Prihatiningrum, 2017). Hasil penelitian Manteiro juga menunjukkan bahwa "Strategi pengembangan desa wisata berbasis kearifan lokal di Kabupaten Rote Ndao perlu memperhatikan hal-hal antara lain Pemasaran paket desa wisata yang menunjukkan nilai jual desa tersebut, pengelolaan desa wisata yang berkelanjutan dan menjaga kelestarian desa wisata itu sendiri sebagai bagian dari potensi desa wisata tersebut. Desa Wisata Feapopi dapat dijadikan alternatif model

\section{BAHAN DAN METODE}

\section{Waktu dan Tempat Pelaksanaan}

Penelitian ini dilaksanakan pada bulan

12 Desember 2018 - 31 Januari 2019. Penelitian ini dilaksanakan di Desa Wonokitri Kecamatan Tosari Kabupaten Pasuruan (Resort PTN Gunung Penanjakan Taman Nasional Bromo Tengger Semeru).

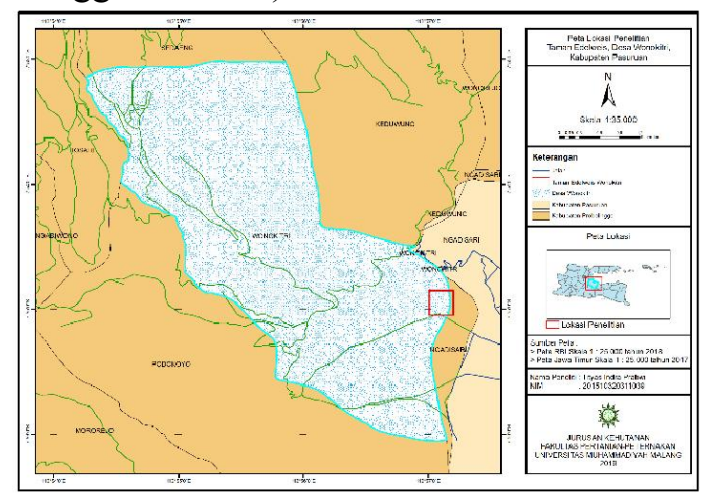

Gambar 1. Peta Desa Wonokitri Kecamatan Tosari Kabupaten Pasuruan

\section{Alat dan Bahan penelitian}

Alat yang digunakan pada penelitian ini yaitu kamera, laptop, kuesioner, dan alat tulis. Bahan yang digunakan pada pengembangan desa wisata alam dan budaya, Desa Wisata Kuli dijadikan alternative model pengembangan desa wisata alam dan Desa Wisata Sotimori dijadikan alternatif model pengembangan desa wisata alam dan budaya" (Manteiro, 2016).

Kesadaran masyarakat yang masih kurang dalam pengembangan Desa Wisata Edelweiss dikarenakan masih dalam tahap awal penerapan desa wisata. Faktor lain adalah kurangnya kesabaran masyarakat dalam membudidayakan Edelweiss. Maka dari beberapa hal tersebut perlu dilakukannya strategi pengembangan dalam pengelolaan desa wisata Edelweiss. Perkembangan ini selain bertujuan untuk menjaga kelestarian Edelweiss digunakan pula untuk melestarikan adat budaya suku Tengger. Penelitian ini bertujuan 1) untuk menentukan strategi pengembangan Desa Wisata Edelweiss, 2) untuk mengetahui partisipasi masyarakat.

penelitian ini yaitu obyek wisata Desa Wisata Edelweiss dan masyarakat Desa Wonokitri.

\section{Metode Pengambilan Data}

Jenis pengambilan data yang diambil yaitu menggunakan kuisioner, wawancara dan dokumentasi. Sedangkan jenis data yang digunakan yaitu menggunkan data primer dan sekunder.

a. Metode Pengambilan Sampel

Menurut Arikunto "terdapat rumus untuk menentukan perkiraan besarnya sampel. Apabila subyeknya kurang dari 100, maka lebih baik diambil semua sehingga penelitiannya merupakan penelitian populasi. Selanjutnya, jika jumlah subyeknya besar dapat diambil antara $10-15 \%$ atau $20-25 \%$ atau lebih, tergantung setidak-tidaknya dari : 1) Kemampuan peneliti dilihat dari waktu, tenaga dan dana. 2) Sempit luasnya wilayah pengamatan dari setiap subyek, karena hal ini menyangkut banyak sedikitnya data. 3) Besar kecilnya resiko yang ditanggung oleh peneliti. Untuk penelitian yang resikonya besar, tentu saja 
jika sampel besar, hasilnya akan lebih baik" (Arikunto, 2002).

Metode pengambilan sampel yang digunakan untuk menentukan jumlah sampel dengan rumus Slovin sebagai berikut : $n=\frac{N}{1+N e^{2}}$

dengan $: \mathrm{n}=$ Jumlah Sampel

$$
\begin{aligned}
& \mathrm{N}=\text { Jumlah Populasi } \\
& \mathrm{e}=\text { Batas Toleransi }
\end{aligned}
$$

Kesalahan (error tolarence)

$$
\begin{aligned}
n=\frac{701}{1+\left(701 \times 0,1^{2}\right)} & =\frac{701}{1+7.01} \\
=87,52 & =100
\end{aligned}
$$

Analisis Data

a. Partisipasi Masyarakat

Analisis yang digunakan yaitu menggunakan analisis deskriptif kuantitatif. Deskriptif yaitu untuk mengumpulkan informasi mengenai status gejala, peristiwa dan kejadian yang apa adanya pada saat penelitian. Penelitian deskriptif digunakan untuk memperkuat hasil yang didapatkan dari penelitian.

b. Strategi pengembangan

Analisis SWOT membandingkan antara faktor eksternal peluang dan ancaman dengan faktor internal kekuatan dan kelemahan. Faktor internal dimasukan kedalam matrik yang disebut IFAS (Internal Factor Analysis Summary). Faktor eksternal dimasukkan kedalam matrik yang disebut EFAS (External Factor Analysis Summary). Setelah IFAS dan EFAS selesai disusun, kemudian hasilnya dimasukkan dalam matrik kuadran SWOT untuk merumuskan strategi kompetitif perusahaan yang disajikan pada Gambar 2.

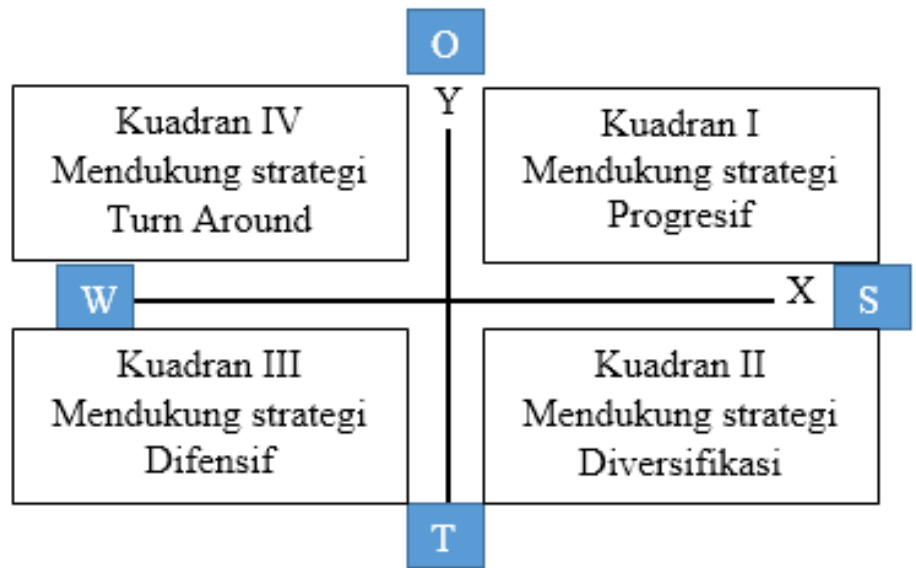

Gambar 2. Matriks kuadran SWOT

Sumber : (Sudarmaji \& Hasan, 2017)

Strategi umum ini dibuat sebagai agar lebih mendukung strategi penguatan pada strategi yang sudah pengembangan, dapat dilihat pada Tabel 1 . ditentukan pada diagram matriks SWOT

Tabel 1. Strategi Umum

\begin{tabular}{|c|c|c|}
\hline Faktor Eksterna & Kekuatan \\
(Strength) S & $\begin{array}{c}\text { Kelemahan } \\
\text { (Weakness }) \\
\text { W }\end{array}$ \\
\hline $\begin{array}{c}\text { Peluang } \\
\text { (Opportunities }) \mathrm{O}\end{array}$ & Strategi SO & Strategi WO \\
\hline $\begin{array}{c}\text { Ancaman } \\
\text { (Threats) } \mathrm{T}\end{array}$ & Strategi ST & Strategi WT \\
\hline
\end{tabular}

HASIL DAN PEMBAHASAN

Strategi Pengembangan Desa Wisata Edelweiss Desa Wonokitri a. Strategi Pengembangan Desa Wisata Edelweiss 
Analisis SWOT digunakan untuk melihat kekuatan, kelemahan, peluang dan ancaman yang akan dihadapi oleh perusahaan (Tamara, 2016). Analisa SWOT menggambarkan situasi dan kondisi yang sedang dihadapi dan mampu memberikan solusi untuk permasalahan yang sedang dihadapi (Rangkuti, 2004).
Dengan menggunakan analisis SWOT suatu lembaga pendidikan dapat mengkaji faktor-faktor yang dapat mempengaruhi kinerja lembaga pendidikan tersebut (Hadi, 2013).

Strategi pengembangan desa wisata Edelweiss Desa Wonokitri dengan analisis swot disajikan pada Tabel 2 dan Tabel 3.

Tabel 2. IFAS (Internal Factor Analysis Summary) Desa Wisata Edelweiss Desa Wonokitri

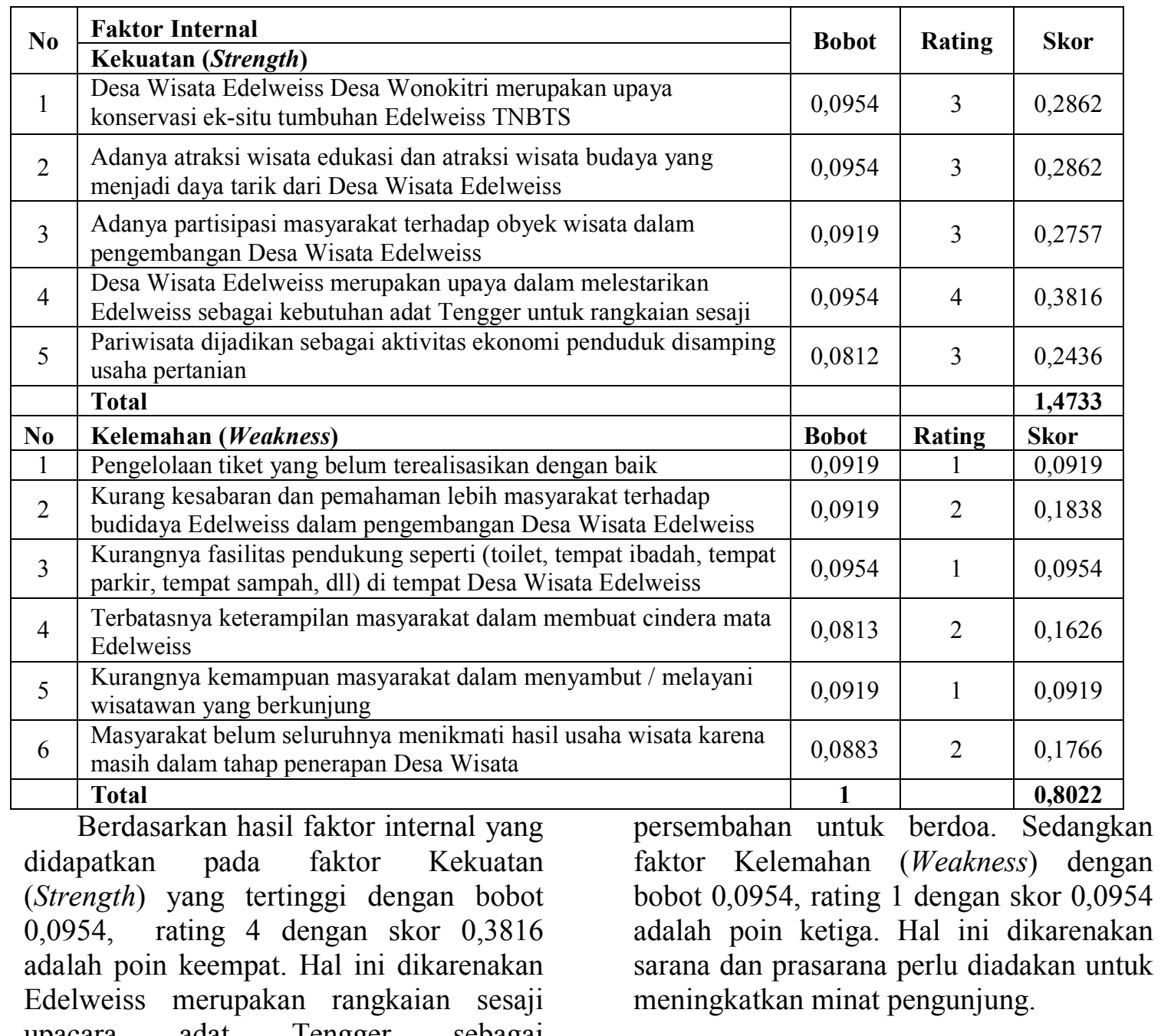




\begin{tabular}{|c|l|c|c|c|}
\hline No & Faktor Eksternal & \multirow{2}{*}{ Bobot } & Rating & Skor \\
\cline { 2 - 4 } 1 & $\begin{array}{l}\text { Peluang (Opportunities) } \\
\text { internasi Desa Wisata Edelweiss sangat mudah diakses melalui } \\
\text { wisata }\end{array}$ & 0,16 & 4 & 0,64 \\
\hline 2 & $\begin{array}{l}\text { Duta Wisata Edelweiss dapat membantu pengembangan Desa } \\
\text { Wisata Edelweiss dalam mempromosikan serta membagi } \\
\text { pengetahuannya }\end{array}$ & 0,1429 & 3 & 0,4287 \\
\hline 3 & $\begin{array}{l}\text { Dukungan pemerintah serta instansi TNBTS terkait peran penting } \\
\text { terhadap pengembangan Desa Wisata Edelweiss }\end{array}$ & 0,16 & 4 & 0,64 \\
\hline Notal sehingga dapat mempromosikan potensi & Ancaman (Threats) & Bobot & Rating & Skor \\
\hline 1 & $\begin{array}{l}\text { Rawan terjadinya bencana longsor yang berbahaya menuju Desa } \\
\text { Wisata Edelweiss }\end{array}$ & 0,1257 & 2 & 0,2514 \\
\hline 2 & $\begin{array}{l}\text { Penawaran desa wisata Edelweiss di tempat lain } \\
\text { Kondisi insfratruktur jalan yang berlubang dan rusak menuju Desa } \\
\text { Wisata Edelweiss }\end{array}$ & 0,1257 & 2 & 0,2514 \\
\hline 4 & $\begin{array}{l}\text { Penanda himbauan atau informasi melalui petunjuk arah tidak ada } \\
\text { untuk menuju Desa Wisata Edelweiss }\end{array}$ & 0,1486 & 2 & 0,2971 \\
\hline & Total & $\mathbf{1}$ & 2 & $\mathbf{1 , 0 7 4 2}$ \\
\hline
\end{tabular}

Berdasarkan hasil faktor eksternal yang didapatkan pada faktor Peluang (Opportunities) yang tertinggi dengan bobot 0,16 , rating 4 dan skor 0,64 yaitu poin ketiga. Adanya dukungan tersebut dapat meningkatkan minat wisatawan melalui promosi kepada wisatawan dengan adanya event-event oleh pemerintah maupun TNBTS, serta dengan dukungan tersebut dapat memberikan hal positif bahwa Desa Wisata Edelweiss layak untuk dikembangkan lebih baik. Sedangkan pada faktor Ancaman (Threats) dengan bobot 0,1486 , rating 2 dan skor 0,2971 yaitu poin keempat. Hal ini dapat membuat menurunnya minat pengunjung yang datang akibat informasi melalui petunjuk arah yang tidak jelas.

Perhitungan SWOT diatas untuk menentukan titik koordinat pada Sumbu X yaitu nilai total kekuatan (S) - kelemahan $(\mathrm{W})=1,47-0,80=0,67$ dan Sumbu $Y$ yaitu nilai total peluang $(\mathrm{O})$ - ancaman $(\mathrm{T})$ $=1,71-1,07=0,64$. Titik koordinat yang didapatkan disajikan pada Gambar 3.

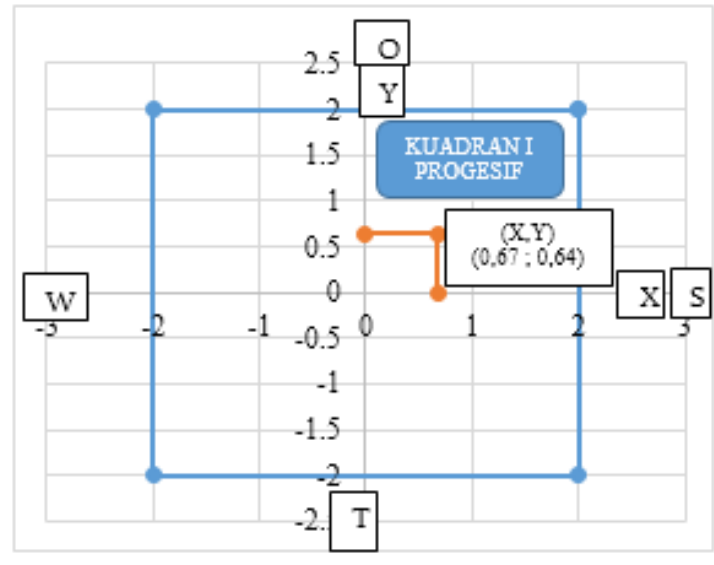

Gambar 3. Matriks Kuadran SWOT Desa Wisata Edelweiss Desa Wonokitri

Pengembangan desa wisata memberikan keuntungan bagi pembangunan ekonomi nasional. Desa yang selama ini identik dengan pertanian maka akan mengalami perubahan paradigma sosial budaya menjadi berbudaya melayani wisatawan. Melayani jasa wisata ini tentu tidak mudah (Nugroho \& Negara, 2015). Dalam usaha mengembangkan pembangunan kepariwisataan, maka kebijakan-kebijakan dalam menggerakan usaha-usaha 
meningkatkan arus kunjungan wisatawan domestik maupun mancanegara perlu didukung oleh peningkatan pemasaran dan promosi kepariwisataan, dan meningkatkan mutu pelayanan, kenyamanan, kebersihan dan keindahan disekitar obyek daya tarik wisata (Mujanah, Ratnawati, \& Andayani, 2016).

Hasil matriks kuadran SWOT Desa Wisata Edelweiss Desa Wonokitri didapatkan titik koordinat $(\mathrm{X} ; \mathrm{Y})(0,67$; $0,64)$ yang terdapat pada posisi kuadran I yaitu Strategi Progresif merupakan situasi yang paling menguntungkan. Strategi pengembangan progresif yang dapat dilakukan dalam pengembangan Desa Wisata Edelweiss yaitu :

1. Mengembangkan wisata menuju Community Based Tourism. Hal yang dilakukan yaitu mengetahui potensi wilayah tersebut dan dikembangkannya wilayah tersebut, program peningkatan kapasitas yang menjadi prioritas utama bagi masyarakat untuk mendukung destinasi serta berpartisipasi secara aktif dalam mengembangkan destinasi pariwisata. Hal lainnya yaitu dengan melakukan pengembangan komunitas yang akan menguatkan kemampuan komunitas masyarakat di dalam desa tersebut untuk mengatur potensi sumberdaya pariwisata, serta fokus untuk melestarikan nilai-nilai kearifan lokal dan lingkungan sekitar.

2. Pemanfaatan dan optimalisasi atraksi wisata dengan tujuan wisata yang mengutamakan unsur pendidikan, konservasi, budaya dan aktivitas ekonomi masyarakat. Pemanfaatan atraksi budaya seperti adanya kesenian rakyat : (Musik Baleganjur, Tari Tani Edelweiss, Tari Ujung), acara tradisional : (Upacara Kuningan, Galungan, Kasodo, Pujan Kesongo, Karo), pangan : (makanan : Nasi Aron, Jadah, Pasung Pipis, Jenang, Bledus), pakaian adat tengger. Hal tersebut bisa dibuat pagelaran seni khas Desa Wonokitri dengan setiap bulannya menjadikan pagelaran wajib untuk dipromosikan, agar memunculkan budaya yang khas dengan adanya Edelweiss tersebut. Melakukan kegiatan penjualan bibit Edelweiss melalui budidaya Edelweiss dapat menjadi peluang terbesar untuk menambah perekonomian masyarakat di Desa Wisata Edelweiss, maka dari itu perlu adanya pembelajaran lebih.

3. Membangun dan memperbaiki sarana serta pemeliharaan prasarana wisata yang dibutuhkan. Pembangunan sarana dan prasana fasilitas pendukung guna sebagai pengembangan yang berkelanjutan seperti tempat ibadah, MCK, dan lahan parkir. Melakukan perbaikan dan pemeliharaan alat, sarana dan perlengkapan wisata secara berkala untuk menunjang daya dukung pengembangan wisata dalam menarik minat wisatawan agar merasa puas. Semua pembangunan dan perbaikan yang dilakukan harus tetap memperhatikan kaidah-kaidah konservasi yang ada.

4. Meningkatkan promosi dan memperbaiki program pengembangan lebih bagus untuk menarik wisatawan. Hal tersebut dapat diwujudkan dengan (a) Materi promosi harus wajar dan obyektif dengan meningkatkan kreatifitas desain untuk meningkatkan daya tarik wisatawan karena pembaca dan pendengar dari kalangan berpendidikan. (b) Mengenalkan sesuatu yang unik, khas atau autentik dengan memasukkan unsur isu budaya lokal, isu konservasi dan jasa unggulan lokal. (c) Dukungan promosi pemerintah melalui partisipasi dalam event-event pameran, iklan wisata, website Pemda, baliho di ruang-ruang publik. Promosi melalui media online menyajikan rubrik wisata dan mengulas tujuan atau produk wisata yang diunggulkan.

5. Melakukan pelatihan pemberdayaan masyarakat untuk menumbuhkan dan 
meningkatkan kesadaran masyarakat tentang pengelolaan desa wisata. Pelatihan yang dilakukan juga yaitu tentang manejemen wisata, kuliner, kerajinan, bahasa dan lain-lain yang dikemas dengan baik dan dapat diterima pengunjung. Pengelolaan wisata harus melakukan pembenahan, pembelajaran kewirausahaan dan peningkatan mutu layanan sesuai kemampuan penduduk desa. Pemberdayaan masyarakat melalui pengembangan kapasitas masyarakat serta peningkatan peran masyarakat yang termasuk dalam konservasi lingkungan, dalam proses perencanaan, pelaksanaan dan evaluasi pengelolaan.

Adapun analisa SWOT penetapan strategi yang digunakan dalam pengembangan Desa Wisata Edelweiss Wonokitri yang disajikan pada Tabel 4 .

Tabel 4. Strategi Umum Desa Wisata Edelweiss Desa Wonokitri

\begin{tabular}{|c|c|c|}
\hline 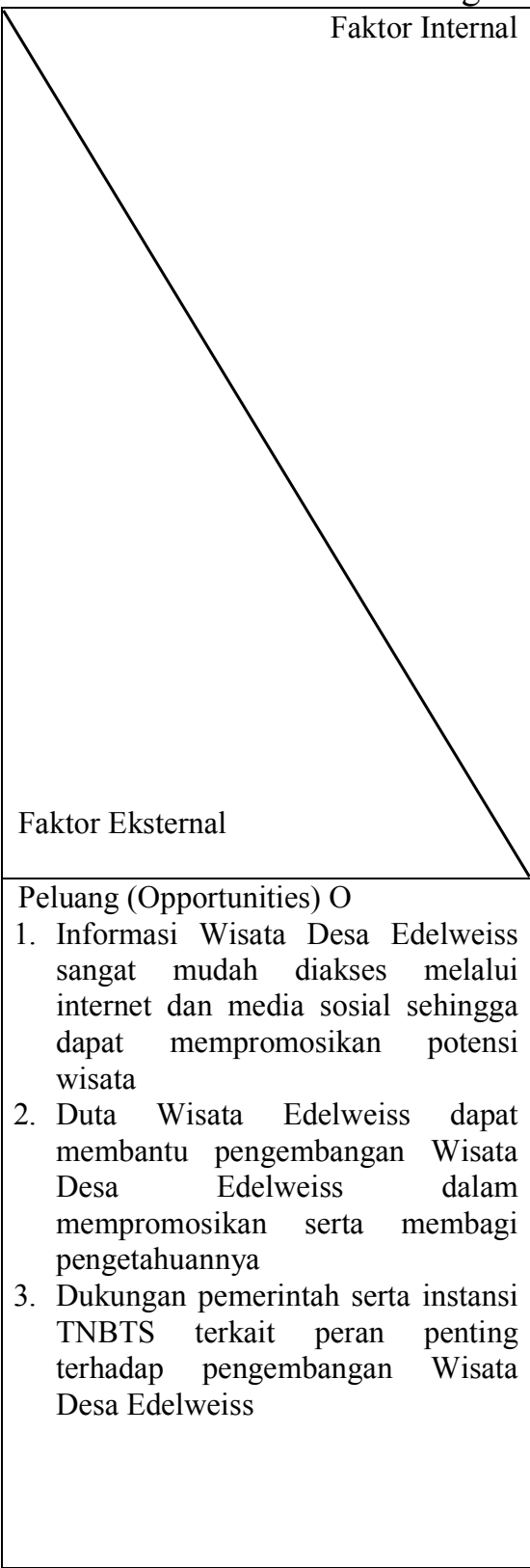 & $\begin{array}{l}\text { Kekuatan (Strength) S } \\
\text { 1. Wisata Desa Edelweiss Desa } \\
\text { Wonokitri merupakan upaya } \\
\text { konservasi ek-situ tumbuhan } \\
\text { Edelweiss TNBTS } \\
\text { 2. Adanya atraksi wisata edukasi dan } \\
\text { atraksi wisata budaya yang menjadi } \\
\text { daya tarik dari Wisata Desa } \\
\text { Edelweiss } \\
\text { 3. Adanya partisipasi masyarakat } \\
\text { terhadap obyek wisata dalam } \\
\text { pengembangan Wisata Desa } \\
\text { Edelweiss } \\
\text { 4. Wisata Desa Edelweiss merupakan } \\
\text { upaya dalam melestarikan } \\
\text { Edelweiss sebagai kebutuhan adat } \\
\text { Tengger untuk rangkaian sesaji } \\
\text { 5. Pariwisata dijadikan sebagai } \\
\text { aktivitas ekonomi penduduk } \\
\text { disamping usaha pertanian }\end{array}$ & 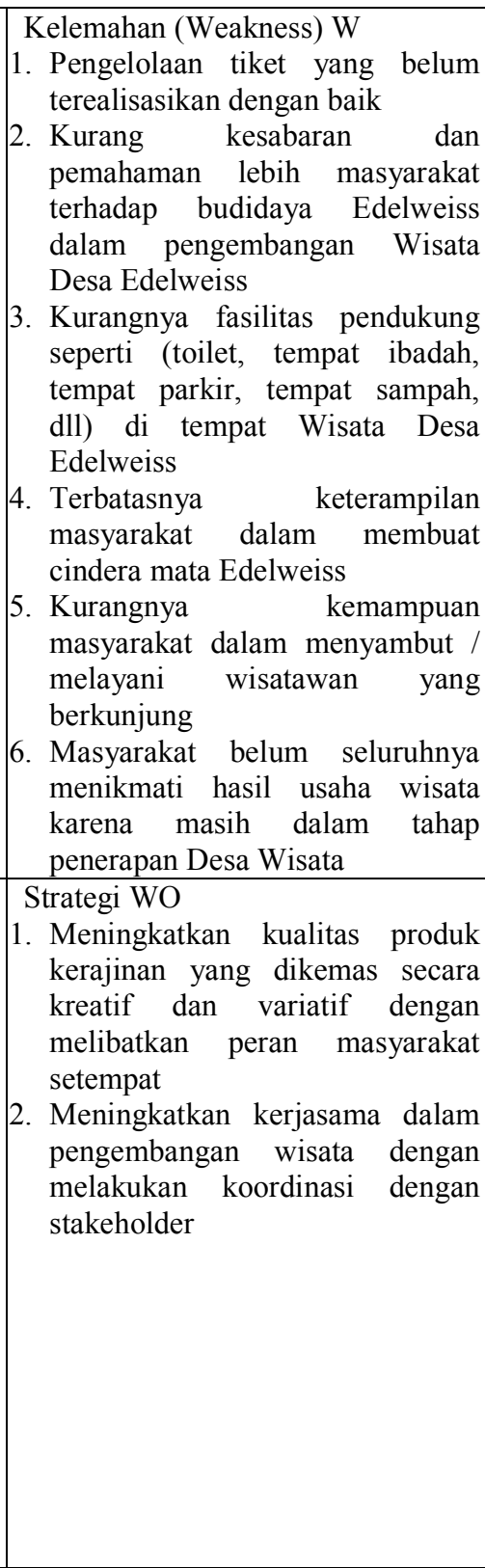 \\
\hline
\end{tabular}




\begin{tabular}{|c|c|c|}
\hline & pengelolaan desa wisata. & \\
\hline $\begin{array}{l}\text { Ancaman (Threats) } \mathrm{T} \\
\text { 1. Rawan terjadinya bencana longsor } \\
\text { yang berbahaya menuju Wisata } \\
\text { Desa Edelweiss } \\
\text { 2. Penawaran desa wisata Edelweiss di } \\
\text { tempat lain } \\
\text { 3. Kondisi insfratruktur jalan yang } \\
\text { berlubang dan rusak menuju Wisata } \\
\text { Desa Edelweiss } \\
\text { 4. Penanda himbauan atau informasi } \\
\text { melalui petunjuk arah tidak ada } \\
\text { untuk menuju Wisata Desa } \\
\text { Edelweiss }\end{array}$ & $\begin{array}{l}\text { Strategi ST } \\
\text { 1. Mengoptimalkan potensi dan } \\
\text { keunikan obyek wisata dengan } \\
\text { mempertahankan wisata budaya } \\
\text { adat tengger dan wisata edukasi } \\
\text { budidaya Edelweiss untuk } \\
\text { menghadapi persaingan antar } \\
\text { obyek wisata Edelweiss }\end{array}$ & \begin{tabular}{|l} 
Strategi WT \\
1. Melakukan pengawasan dan \\
pemeliharaan fasilitas-fasilitas \\
yang sudah ada
\end{tabular} \\
\hline
\end{tabular}

\section{b. Partisipasi Masyarakat}

\section{Karakteristik Masyarakat}

1. Jenis Kelamin

Data yang dikumpulkan berdasarkan jenis kelamin disajikan pada Tabel 5.

Tabel 5. Jenis kelamin responden

\begin{tabular}{|c|c|c|}
\hline $\begin{array}{c}\text { Jenis } \\
\text { Kelamin }\end{array}$ & $\begin{array}{c}\text { Jumlah } \\
\text { (orang) }\end{array}$ & $\begin{array}{c}\text { Persentase } \\
(\%)\end{array}$ \\
\hline Laki-laki & 53 & 53 \\
\hline Perempuan & 47 & 47 \\
\hline Total & $\mathbf{1 0 0}$ & $\mathbf{1 0 0}$ \\
\hline
\end{tabular}

Jenis kelamin pada 100 responden didominasi oleh laki-laki 53 orang yang terbagi 13 orang dari Kelompok Tani Edelweiss dan 40 orang masyarakat biasa dengan persentase total $53 \%$ dikarenakan saat penelitian kebanyakan yang dapat ditemui di lapang bekerja di bidang pariwisata maupun pertanian, sedangkan perempuan 47 orang yang terbagi 7 orang Kelompok Tani Edelweiss dan 40 orang masyarakat biasa dengan persentase total 47\% dapat ditemui diperkumpulan PKK dan malam hari selesai bertani. Sehingga 20 orang termasuk dalam Kelompok Tani Edelweiss.

2. Umur

Data yang dikumpulkan berdasarkan umur disajikan pada Tabel 6 .
Tabel 6. Jumlah umur responden

\begin{tabular}{|l|c|c|c|}
\hline \multirow{2}{*}{ Umur } & \multicolumn{2}{|c|}{ Jumlah (orang) } & Persentase \\
\cline { 2 - 3 } & $\mathbf{L}$ & $\mathbf{P}$ & \\
\hline $\begin{array}{l}15-24 \\
\text { tahun }\end{array}$ & 14 & 22 & 36 \\
\hline $\begin{array}{l}25-34 \\
\text { tahun }\end{array}$ & 21 & 14 & 35 \\
\hline $\begin{array}{l}35-44 \\
\text { tahun }\end{array}$ & 13 & 7 & 20 \\
\hline $\begin{array}{l}45-54 \\
\text { tahun }\end{array}$ & 4 & 4 & 8 \\
\hline $\begin{array}{l}55-64 \\
\text { tahun }\end{array}$ & 0 & 0 & 0 \\
\hline $\begin{array}{l}>65 \\
\text { tahun }\end{array}$ & 1 & 0 & 1 \\
\hline Total & $\mathbf{5 3}$ & $\mathbf{4 7}$ & $\mathbf{1 0 0}$ \\
\hline
\end{tabular}

Berdasarkan hasil penelitian yang didapatkan umur yang mendominasi 15-24 tahun dengan persentase total $36 \%$ jumlah 14 laki-laki dan 22 perempuan diantaranya 4 orang laki-laki dan 6 orang perempuan merupakan Kelompok Tani Edelweiss, kebanyakan masyarakat Desa Wonokitri kisaran umur 15-24 tahun sudah bekerja, bahkan masyarakat kisaran umur 15-24 tahun melakukan sekolah sambil bekerja membantu perekonomian keluarga. Diikuti kisaran umur 25-34 tahun dengan jumlah laki-laki 21 orang dan perempuan 14 orang dengan persentase total $35 \%$ tertinggi kedua diantaranya 8 orang laki-laki dan 1 orang perempuan merupakan Kelompok Tani Edelweiss, hal tersebut dapat dikatakan umur yang produktif untuk melakukan aktivitas sehari-hari. Selanjutnya kisaran umur 35-44 tahun dengan jumlah laki-laki 13 orang dan perempuan 7 orang dengan persentase total 
$20 \%$ yang diantaranya 1 orang laki-laki merupakan Kelompok Tani Edelweiss, 4554 tahun dengan jumlah laki-laki 4 orang dan perempuan 4 orang dengan persentase total 8\%, 55-64 tahun dengan persentase $0 \%,>65$ tahun dengan jumlah laki-laki 1 orang dengan persentase total $1 \%$.

3. Tingkat Pendidikan

Data yang dikumpulkan berdasarkan tingkat pendidikan disajikan pada Tabel 7.

Tabel 7. Tingkat pendidikan responden

\begin{tabular}{|l|c|c|c|}
\hline \multirow{2}{*}{ Pendidikan } & \multicolumn{2}{|c|}{ Jumlah (orang) } & Persentase \\
\cline { 2 - 3 } & $\mathbf{L}$ & $\mathbf{P}$ & \\
\hline $\begin{array}{l}\text { Tidak } \\
\text { Sekolah }\end{array}$ & 1 & 0 & 1 \\
\hline SD & 21 & 13 & 34 \\
\hline SMP & 14 & 16 & 30 \\
\hline SMA & 13 & 13 & 26 \\
\hline $\begin{array}{l}\text { Sarjana } \\
\text { (S1) }\end{array}$ & 4 & 5 & 9 \\
\hline Total & $\mathbf{5 3}$ & $\mathbf{4 7}$ & $\mathbf{1 0 0}$ \\
\hline
\end{tabular}

Tingkat pendidikan memiliki status sosial yang tinggi bagi kalangan masyarakat, sehingga jika tingkat pendidikan tinggi maka status sosial masyarakat juga tinggi. Berdasarkan hasil yang didapat yaitu 34 responden dari 21 orang laki-laki dan 13 orang perempuan yang diantaranya 2 orang laki-laki dan 1 orang perempuan merupakan Kelompok Tani Edelweiss dengan persentase total $34 \%$ masyarakat Desa Wonokitri berpendidikan sekolah dasar, hal tersebut dapat dikatakan tingkat pendidikannya rendah atau dapat dikatakan kurang. Saat ini masyarakat berlahan membuka pemikiran untuk dapat menerima masukan bahkan pelatihan-pelatihan yang diberikan pemerintah untuk meningkatkan pengetahuannya. Tingkat SMP dengan jumlah 30 responden dari 14 orang lakilaki dan 16 orang perempuan yang diantaranya 1 orang laki-laki dan 1 orang perempuan merupakan Kelompok Tani Edelweiss dengan persentase total $30 \%$, tingkat SMA dengan jumlah 26 responden dari 13 orang laki-laki dan 13 orang perempuan yang diantaranya 6 orang lakilaki dan 3 orang perempuan merupakan Kelompok Tani Edelweiss dengan persentase total $26 \%$, tingkat S1 dengan jumlah 9 responden dari 4 orang laki-laki dan 5 orang perempuan yang diantaranya 3 orang laki-laki dan 3 orang perempuan merupakan Kelompok Tani Edelweiss persentase $9 \%$ dan tidak sekolah yang diantaranya 1 orang laki-laki dengan persentase total $1 \%$.

4. Pekerjaan

Data yang dikumpulkan berdasarkan pekerjakan disajikan pada Tabel 8 . Tabel 8. Pekerjaan responden

\begin{tabular}{|l|c|c|c|}
\hline \multirow{2}{*}{ Pekerjaan } & \multicolumn{2}{|c|}{ Jumlah (orang) } & Persentase \\
\cline { 2 - 3 } & $\mathbf{L}$ & $\mathbf{P}$ & $\mathbf{( \% )}$ \\
\hline $\begin{array}{l}\text { Pelajar/ } \\
\text { Mahasiswa }\end{array}$ & 4 & 8 & 12 \\
\hline Petani & 40 & 26 & 66 \\
\hline Wiraswasta & 8 & 13 & 21 \\
\hline PNS & 1 & 0 & 1 \\
\hline Total & $\mathbf{5 3}$ & $\mathbf{4 7}$ & $\mathbf{1 0 0}$ \\
\hline
\end{tabular}

Berdasarkan hasil penelitian yang didapatkan pekerjaan masyarakat Desa Wonokitri mayoritas adalah 66 responden sebagai petani dari 40 orang laki-laki dan 26 orang perempuan yang diantaranya 7 orang laki-laki dan 5 otang perempuan merupakan Kelompok Tani Edelweiss dengan persentase total $66 \%$, dikarenakan petani adalah pekerjaan utama dalam mencari nafkah mereka. Hasil wawancara yang dilakukan selain pekerjaan utama sebagai petani mereka melakukan pekerjaan sampingan yaitu sebagai pelaku wisata. Pekerjaan sampingan menjadi pelaku wisata ini juga menjadi aktifitas yang dilakukan untuk menambah ekonomi. Bahkan menyita waktu yaitu pada pagi hingga sore hari harus dan sore harinya hingga pagi harinya bekerja sebagai pelaku wisata. Selanjutnya pekerjaan sebagai wiraswasta 21 responden dari 8 orang lakilaki dan 13 orang perempuan yang diantaranya 5 orang laki-laki dan 2 orang perempuan merupakan Kelompok Tani Edelweiss dengan persentase total $21 \%$ ini juga dilakukan untuk menambah ekonomi. Beberapa hasil penelitian juga sebagai pelajar/mahasiswa 12 responden dari 4 orang laki-laki dan 8 orang perempuan dengan persentase $12 \%$, serta $1 \%$ sebagai PNS yaitu ASN (Aparatur Sipil Negara) 
yang termasuk 1 orang laki-laki merupakan Kelompok Tani Edelweiss.

5. Pendapatan
Data yang dikumpulkan berdasarkan pendapatan disajikan pada Tabel 9.

Tabel 9. Pendapatan perbulan responden

\begin{tabular}{|l|c|c|c|}
\hline \multirow{2}{*}{ Pendapatan perbulan } & \multicolumn{2}{|c|}{ Jumlah (orang) } & \multirow{2}{*}{ Persentase (\%) } \\
\cline { 2 - 4 } & $\begin{array}{c}\text { Kelompok Tani } \\
\text { Edelweiss }\end{array}$ & $\begin{array}{c}\text { Bukan } \\
\text { Kelompok Tani }\end{array}$ & \\
\hline$<$ Rp. 1.000 .000 & 9 & 35 & 44 \\
\hline Rp. $1.000 .000-$ Rp. 2.000 .000 & 8 & 20 & 28 \\
\hline Rp. $2.000 .000-$ Rp. 3.000 .000 & 3 & 12 & 15 \\
\hline Rp. 3.000.000-Rp. 4.000 .000 & 0 & 5 & 5 \\
\hline >Rp. 4.000.000 & 0 & 0 & 0 \\
\hline Tidak berpenghasilan & 0 & 8 & 8 \\
\hline Total & $\mathbf{2 0}$ & $\mathbf{8 0}$ & $\mathbf{1 0 0}$ \\
\hline
\end{tabular}

Hasil tersebut menyatakan dengan pendapatan perbulan $<$ Rp. $\quad 1.000 .000$ persentase total $44 \%$ dengan jumlah 44 responden diantaranya 9 orang Kelompok Tani Edelweiss dan 35 orang bukan Kelompok Tani Edelweiss. Pendapatan perbulan Rp. 1.000.000 - Rp. 2.000 .000 dengan persentase total $28 \%$ dengan jumlah 28 responden diantaranya 8 orang Kelompok Tani dan 20 orang bukan Kelompok Tani Edelweiss. Pendapatan perbulan Rp. 2.000.000 - Rp. 3.000 .000 dengan persentase total $15 \%$ dengan jumlah 15 orang diantaranya 3 orang Kelompok Tani Edelweiss dan 12 orang bukan Kelompok Tani Edelweiss. Hal ini dapat dikatakan pendapatan Kelompok Tani Edelweiss cukup rendah. Pendapatan di Kelompok Tani Edelweiss yang tidak menentu tersebut mereka jadikan pekerjaan sampingan mereka karena adanya pekerjaan utama mereka sebagai petani. Tetapi akan hal itu tidak menurunkan semangat mereka untuk menjadikan pekerjaan sebagai Kelompok Tani Edelweiss sebagai pekerjaan yang unggul untuk membangun Desa Wisata Edelweiss. Bagi masyarakat yang bukan Kelompok Tani Edelweiss juga dapat dikatakan rendah karena pendapatan $<\mathrm{Rp}$. 1.000.000 sebagai petani kentang yang tidak menentu dengan hasil panen 4 bulan sekali untuk mendapatkan uang, maka dari itu mereka melakukan pekerjaan sampingan menjadi pelaku wisata dan juga berdagang. Pendapatan Rp. 3.000.000 Rp. 4.000 .000 dengan persentase 5\% dengan jumlah 5 orang bukan Kelompok Tani Edelweiss dapat dikatakan cukup tinggi, karena pekerjaannya bukan sebagai petani saja tetapi adanya pekerjaan sampingan sebagai pelaku wisata seperti adanya homestay dan berdagang membuat peningkatan pendapatan semakin tinggi. Tidak berpenghasilan dengan persentase $8 \%$ dengan jumlah 8 orang merupakan masyarakat yang masih bersekolah sebagai pelajar atau mahasiswa.

Partisipasi Masyarakat

Berdasarkan hasil penelitian yang dilakukan kepada 100 responden yaitu disajikan pada Tabel 10 
Tabel 10. Partisipasi responden terhadap Desa Wisata Edelweiss

\begin{tabular}{|c|c|c|c|c|}
\hline $\begin{array}{c}\text { Partisipasi } \\
\text { Masyarakat }\end{array}$ & Pernyataan & $\begin{array}{l}\mathbf{S} \\
(\%)\end{array}$ & $\begin{array}{l}\text { KK } \\
(\%)\end{array}$ & $\begin{array}{l}\text { TP } \\
(\%)\end{array}$ \\
\hline \multirow{5}{*}{$\begin{array}{c}\text { Tahap } \\
\text { Perencanaan }\end{array}$} & a. Saya mengikuti pertemuan atau sosialisasi pariwisata & 8 & 41 & 51 \\
\hline & $\begin{array}{l}\text { b. Saya mengikuti rapat dan berkonsultasi dengan pihak } \\
\text { pengelola taman nasional atau pemerintah mengenai } \\
\text { pengembangan Desa Wisata Edelweiss Desa } \\
\text { Wonokitri }\end{array}$ & 15 & 7 & 78 \\
\hline & $\begin{array}{lllr}\text { c. } & \text { Saya memberikan informasi dan ikut } \\
\text { mengidentifikasi potensi wisata yang ada di } & \text { Desa } \\
\text { Wisata Edelweiss Desa Wonokitri } & & \\
\end{array}$ & 18 & 21 & 61 \\
\hline & $\begin{array}{l}\text { d. Saya menyampaikan pendapat atau mengusulkan } \\
\text { rencana atau ide terkait pengembangan Desa Wisata } \\
\text { Edelweiss Desa Wonokitri }\end{array}$ & 11 & 22 & 67 \\
\hline & \begin{tabular}{|llcr} 
e. & Saya terlibat dalam penyusunan & anggaran \\
& pembangunan di Desa Wisata Edelweiss
\end{tabular} & 13 & 8 & 79 \\
\hline Total & & 13 & 19,8 & 67,2 \\
\hline \multirow{4}{*}{$\begin{array}{l}\text { Tahap } \\
\text { Pelaksanaan } \\
\text { Pembangunan }\end{array}$} & $\begin{array}{l}\text { a. Saya terlibat dalam kegiatan perbaikan infrastruktur } \\
\text { di Desa Wisata Edelweiss }\end{array}$ & 14 & 33 & 53 \\
\hline & $\begin{array}{l}\text { b. Saya turut memberikan sumbangan berupa uang } \\
\text { (iuran) atau makanan dan minuman dalam berbagai } \\
\text { kegiatan pembangunan di Desa Wisata Edelweiss }\end{array}$ & 16 & 20 & 64 \\
\hline & \begin{tabular}{|l} 
c. Saya terlibat dalam setiap pengambilan keputusan \\
mengenai pengembangan Desa Wisata Edelweiss
\end{tabular} & 15 & 6 & 79 \\
\hline & $\begin{array}{l}\text { d. Saya mengikuti pelatihan pariwisata atau kursus } \\
\text { bahasa asing guna meningkatkan keterampilan dalam } \\
\text { bidang pariwisata }\end{array}$ & 3 & 17 & 80 \\
\hline Total & & 12 & 19 & 69 \\
\hline \multirow{4}{*}{$\begin{array}{c}\text { Tahap } \\
\text { Pengelolaan }\end{array}$} & $\begin{array}{l}\text { a. Saya turut berpartisipasi dalam mengelola pariwisata } \\
\text { di Desa Wisata Edelweiss, yang meliputi juru parkir, } \\
\text { keamanan, guide, homestay, dll. }\end{array}$ & 20 & 60 & 20 \\
\hline & $\begin{array}{l}\text { b. Saya ikut berpartisipasi dalam pembangunan fasilitas } \\
\text { penunjang pariwisata di Desa Wisata Edelweiss }\end{array}$ & 12 & 15 & 73 \\
\hline & $\begin{array}{ll}\text { c. Saya turut membantu mempromosikan Desa Wisata } \\
\text { Edelweiss }\end{array}$ & 30 & 31 & 39 \\
\hline & \begin{tabular}{|l} 
d. Saya mendukung kegiatan pariwisata yang telah \\
ditentukan dengan baik
\end{tabular} & 90 & 10 & 0 \\
\hline Total & & 38 & 29 & 33 \\
\hline \multirow{4}{*}{$\begin{array}{l}\text { Tahap } \\
\text { Monitoring dan } \\
\text { Evaluasi }\end{array}$} & $\begin{array}{l}\text { a. Saya ikut mengawasi kegiatan pariwisata di Desa } \\
\text { Wisata Edelweiss }\end{array}$ & 20 & 11 & 69 \\
\hline & $\begin{array}{ll}\text { b. Saya ikut mengawasi tindakan-tindakan negatif yang } \\
\text { dapat merusak citra Desa Wisata Edelweiss }\end{array}$ & 23 & 28 & 49 \\
\hline & $\begin{array}{ll}\text { c. Saya ikut mengevaluasi penyelenggaraan pariwisata } \\
\text { di Desa Wisata Edelweiss }\end{array}$ & 16 & 8 & 76 \\
\hline & \begin{tabular}{|lll} 
d. Saya terlibat dalam kegiatan penelitian dan \\
pengembangan serta menyusun laporan evaluasi
\end{tabular} & 13 & 7 & 80 \\
\hline Total & & 18 & 13,5 & 68,5 \\
\hline \multicolumn{5}{|c|}{$\begin{array}{ll}\text { Pentingnya partisipasi masyarakat } & \text { teridentifikasi melalui } \mathrm{S}=\text { Selalu, } \mathrm{KK}= \\
\mathrm{m} \text { pengambilan keputusan sehingga } & \text { Kadang-kadang, dan TP = Tidak Pernah. } \\
\text { yarakat akan selalu diikutsertakan atau } & \text { Hasil tersebut secara penyebaran kuisioner } \\
\text { batkan dalam suatu diskusi ataupun } & \text { dan wawancara didapatkan bahwa dari } \\
\text { it. Hal ini dikarenakan bahwa setiap } & \text { keempat tahap yang ada yaitu tahap } \\
\text { bangunan akan berhasil jika ada } & \text { perencanaan, tahap pelaksanaan dan } \\
\text { isipasi dan dukungan sepenuhnya dari } & \text { pembangunan, tahap pengelolaan, serta } \\
\text { yarakat (Hakim, 2017). Berdasarkan } & \text { tahap monitoring dan evaluasi dapat } \\
\text { el 4.9. Partisipasi responden terhadap } & \text { disimpulkan bahwa pada tahap } \\
\text { a Wisata Edelweiss yang } & \end{array}$} \\
\hline
\end{tabular}


pengelolaan tingkat partisipasinya lebih banyak.

Tahap pengelolaan tingkat partisipasinya lebih banyak dari total persentase yaitu 38\% (S) Selalu, 29\% (KK) Kadang-kadang, dan 33\% (TP) Tidak Pernah yang dijabarkan pada persentase $20 \%$ menyatakan (S) selalu turut berpartisipasi dan tergabung dalam kelompok tani Hulun Hyang \pm 20 orang ikut dalam mengelolah Desa Wisata Edelweiss binaan dari Taman Nasional Bromo Tengger Semeru (TNBTS). Sedangkan persentase $60 \%$ menyatakan (KK) Kadang-kadang yaitu masyarakat ikut berpartisipasi dalam penanaman Edelweiss di depan rumah masing-masing, hal ini dilakukan kebanyakan masyarakat Desa Wonokitri untuk berpartisipasi dalam pengembangan Desa Wisata Edelweiss, dikarenakan pemerintah desa mewajibkan bagi masyarakat Desa Wonokitri untuk menanam Edelweiss di depan rumah masing-masing minimal 3 bibit. Masyarakat juga melakukan penanaman di sepanjang jalan Desa Wonokitri. Masyarakat menanam, menjaga dan merawat Edelweiss yang ada di KRPL (Kawasan Rumah Pangan Lestari) RT/RW di Desa Wonokitri yang berdampingan dengan tanaman-tanaman toga, maupun tanaman sayuran, hal tersebut kebanyakan dilakukan oleh ibu-ibu PKK. Kegiatan PKK yang dilakukan tersebut sudah termasuk program yang telah disetujui oleh pemerintah Desa Wonokitri dalam pengembangan tanaman Edelweiss.

Tahap perencanaan tingkat partisipasinya kecil dilihat dari total persentase yaitu 13\% (S) Selalu, 19,8\% (KK) Kadang-kadang, dan 67,2\% (TP) Tidak Pernah. Hal ini dikarenakan masyarakat masih kurang berpartisipasi dalam perencanaannya dan kemampuan masyarakat belum menyampai tahap perencanaan, tetapi berpartisipasi saat pengelolaan di lapangnya karena jika dilakukan perencanaan lebih lanjut mereka belum mampu. Serta masih dilakukan oleh Kelompok Tani Hulun Hyang serta beberapa tokoh masyarakat dan pemeritah desa.

Tahap pelaksanaan dan pembangunan dilihat dari total persentase yaitu $12 \%$ (S) Selalu, 19\% (KK) Kadang-kadang, dan $69 \%$ (TP) Tidak Pernah. Dapat disimpulkan tingkat partisipasinya juga kecil karena masyarakat yang bukan tergolong dalam Kelompok Tani Hulun Hyang tidak banyak terlibat dalam pelaksanaan bahkan pembangunannya. Hal ini dikarenakan masyarakat yang bukan tergolong dalam kelompok tani Hulun Hyang yang mayoritas pekerjaan utamanya sebagai petani tidak ada banyak waktu untuk ikut terjun dalam pelaksanaan dan pembangunannya.

Tahap Monitoring dan evaluasi dilihat dari total persentase yaitu 18\% (S) Selalu, 13,5\% (KK) Kadang-kadang, dan 68,5\% (TP) Tidak Pernah. Hal tersebut dikatakan tingkat partisipasinya kecil, tetapi di tahap ini beberapa masyarakat ikut mengawasi tindakan-tindakan negatif yang dapat merusak citra Desa Wonokitri. Masyarakat yang terlibat dalam kegiatan penelitian dan pengembangan serta menyusun laporan evaluasi dinyatakan sedikit dikarenakan masyarakat yang tergolong Kelompok Tani Hulun Hyang telah melakukan kegiatan tersebut yang dilakukan bersama pihak TNBTS maupun pemerintah desa dalam pengembangan Desa Wisata Edelweiss.

\section{KESIMPULAN}

1. Pengembangan pada Desa Wisata Edelweiss Wonokitri dilakukan Pengembangkan wisata menuju Community Based Tourism; Pemanfaatan dan optimalisasi atraksi wisata dengan tujuan wisata yang mengutamakan unsur pendidikan, konservasi, budaya dan aktivitas ekonomi masyarakat; Membangun dan memperbaiki sarana serta pemeliharaan prasarana wisata yang dibutuhkan; dan Meningkatkan promosi dan memperbaiki program pengembangan lebih bagus untuk 
menarik wisatawan; serta Melakukan pelatihan pemberdayaan masyarakat untuk menumbuhkan dan meningkatkan kesadaran masyarakat tentang pengelolaan desa wisata.

2. Bentuk partisipasi masyarakat yaitu \pm 20 orang menjadi anggota Kelompok Tani Edelweiss dalam mengelolah

\section{DAFTAR PUSTAKA}

Andajani, E., Widjaja, F. N., \& Prihatiningrum, A. E. 2017. Pengembangan Potensi Desa Wisata melalui Analisa SWOT Di Kecamatan Kalitidu Bojonegoro. Seminar Nasional dan Gelar Produk 2, 909915.

Arikunto, S. 2002. Metodologi Penelitian Suatu Pendekatan Proposal. Jakarta: PT. Rineka Cipta.

Devy, H. A., \& Soemanto, R. B. 2017. Pengembangan Obyek Dan Daya Tarik Wisata Alam Sebagai Daerah Tujuan Wisata Di Kabupaten Karanganyar. Jurnal Sosiologi DILEMA, Vol. 32, No. 1 Tahun 2017, 32(1), 34-44.

Hadi, A. 2013. Konsep Analisis SWOT dalam Peningkatan Mutu Lembaga Madrasah. Jurnal Ilmiah DIDAKTIKA, 14(1), 143-158.

Hakim, L. 2017. Partisipasi Masyarakat dalam Pembangunan Desa Sukamerta Kecamatan Rawamerta Kabupaten Karawang. Jurnal Politikom Indosiana, 2(2), 43.

Manteiro, M. C. B. 2016. Model Pengembangan Desa Wisata Berbasis Kearifan Lokal Sebagai Strategi Pengentasan Kemiskinan Di Kabupaten Rote Ndao Nusa Tenggara Timur. Jurnal Bisnis dan Manajemen, 2(2), 93-101.

Mujanah, S., Ratnawati, T., \& Andayani, S. 2016. Strategi Pengembangan
Desa Wisata Edelweiss dan masyarakat yang tidak masuk Kelompok Tani hanya berpartisipasi menanam Edelweiss di depan rumah dan sepanjang jalan serta sekedar mempromosikan Desa Wisata Edelweiss.

Desa Wisata Di Kawasan Hinterland Gunung Bromo Jawa Timur. Jurnal Hasil Penelitian LPPM UNTAG Surabaya Fakultas Ekonomi Universitas 17 Agustus 1945 Surabaya, 01(01), 33-52.

Nugroho, I., \& Negara, P. D. 2015. Pengembangan Desa Melalui Ekowisata. (R. N. Hamidawati, Ed.). Surakarta: PT Era Adicitra Intermedia.

Primanita, D., Antariksa, A., \& Wardani, D. K. 2011. Kearifan Lokal Masyarakat Suku Tengger dalam Pemanfaatan Ruang dan Upaya Pemeliharaan Lingkungan (Studi Kasus Desa Wonokitri, Kecamatan Tosari, Kabupaten Pasuruan). Jurusan Perencanaan Wilayah dan Kota Fakultas Teknik Universitas Brawijaya Malang.

Rangkuti, F. 2004. Analisis SWOT Teknik Membedah Kasus Bisnis. Jakarta: PT. Gramedia.

Sudarmaji, I., \& Hasan, W. 2017. Strategi Pengembangan Keterkaitan Kebun Inti Plasma dengan Kapasitas Pabrik Kelapa Sawit pada Perkebunan PT. Kurnia Luwuk Sejati Banggai Sulawesi Tengah. Jurnal Galung Tropika, 6(1), 33-41.

Tamara, A. 2016. Implementasi Analisis Swot dalam Strategi Pemasaran Produk Mandiri Tabungan Bisnis. Jurnal Riset Bisnis dan Manajemen, 4(3), 395-406. 